\title{
Analysis of the Resistance of Thin-Walled Cold-Formed Compressed Steel Members with Closed Cross-sections. Part 2
}

PhD, Ing., head of the department Al Ali Mohamad; PhD, Doc. Ing., head of the department Michal Tomko,

Technical University in Košice

\begin{abstract}
Part 1 of the paper presents fundamental information about the experimental and theoretical research oriented to determine the resistance of thin-walled cold-formed compressed steel members with closed cross-sections, [1]. The investigated members were made from homogeneous material. The theoretical analysis was oriented to determine the resistance of mentioned members according to European and Slovak standards, while the experimental investigation was to verify the theoretical results and to investigate the behavior of the above-mentioned members during the loading process, [2]. Part 2 is focused on the numerical analysis of the achieved results, as well as on 3D modeling and simulation of the experimental tests.
\end{abstract}

Key words: thin-walled web; cold-formed profiles; initial imperfections

\section{Introduction}

The first paper "Analysis of the resistance of thin-walled cold-formed compressed steel members with closed cross-sections - Part 1", brought a global overview of the achieved results and presented the differences between the results of experimental tests and other results, obtained according to different calculation methods. Because of the mentioned differences, it was necessary to carry out a detailed numerical analysis to clarify the identified deficiencies. The numerical analysis has been oriented towards the investigation and modelling of initial imperfections, caused by production processes, on the loadbearing capacities of the mentioned members. This analysis was based on the modelling of actually measured initial imperfections as spatial areas, also on the 3D simulation of the experimental tests with non-linear calculation procedures using software ANSYS based on the FEM, [3]. The results are very extensive; therefore the paper deals only with Cross-sectional group B2, Table 1 and Figure 1.

Table 1. Dimensions and material characteristics, Cross-sectional group B2

\begin{tabular}{|c|c|c|c|c|c|c|c|}
\hline \multirow{2}{*}{ Tested member } & b & h & $\mathbf{t}$ & $\mathbf{r}$ & $\mathbf{L}$ & $\mathbf{f}_{\mathbf{y}}$ & $\mathbf{f}_{\mathbf{u}}$ \\
\cline { 2 - 9 } & \multicolumn{6}{|c|}{$[\mathbf{m m}]$} & \multicolumn{2}{c|}{ [ MPa ] } \\
\hline B21 & 207,93 & 103,08 & 2,12 & 3,0 & 650,00 & 242,33 & 360,00 \\
\hline B22 & 207,47 & 103,18 & 2,10 & 3,0 & 649,88 & 242,33 & 360,00 \\
\hline B23 & 207,35 & 102,62 & 2,16 & 3,0 & 649,25 & 242,33 & 360,00 \\
\hline
\end{tabular}

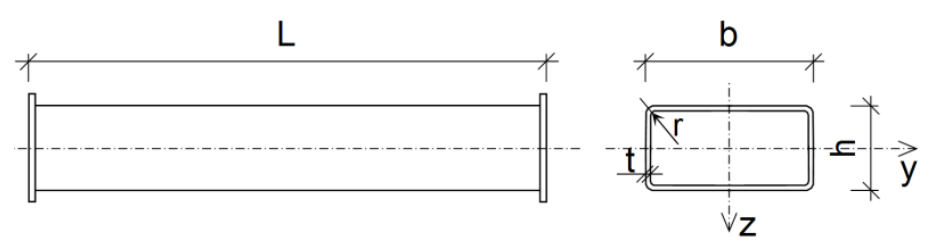

Figure 1. Scheme of the tested members; Cross-sectional group B

\section{Analysis of the size and shape of initial imperfections}

As it was stated in the first part, [1] experimental limit loads were smaller than the expected theoretical values for all tested members. One of the possible implications was due to the size and shape of initial (production) imperfections. In terms of tolerance, the maximal discrete measured initial imperfection of the webs was $1,51 \mathrm{~mm}$ and the maximal tolerated imperfection is given in the standard as $\mathrm{b} / 50$, which is $4,15 \mathrm{~mm}$, [4]. It follows that the problem is not in the size of these imperfections but in their distribution and shape.

The referred standard, EN 1090-2 + A1:2012, permits a maximal tolerated value b/50 for imperfections in a sinusoidal waves form as shown in Figure 2. 
The initial imperfections of all tested members were modelled in the mathematical software MATLAB as spatial areas. The results showed that none of the webs had uniform initial imperfection shapes, and not at all of a sinusoidal waves form. Figures 3 and 4 illustrate the shape of initial imperfections for the relevant webs of member B21. Midline initial imperfections of all webs are illustrated by graphs in Figure 5.

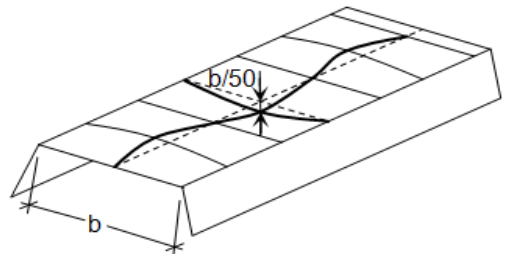

Figure 2. Tolerated initial imperfections according to [4]

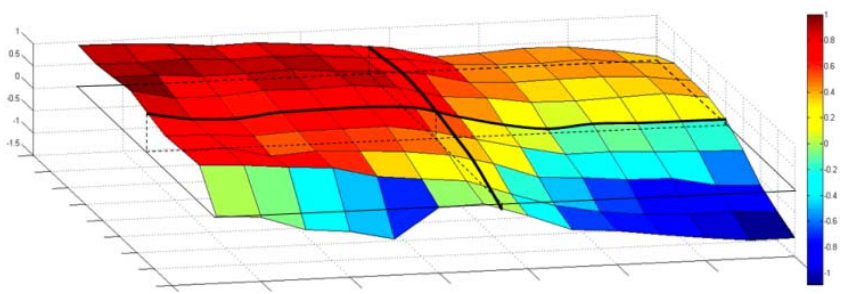

Figure 3. Initial imperfections shape of member B21, web 1

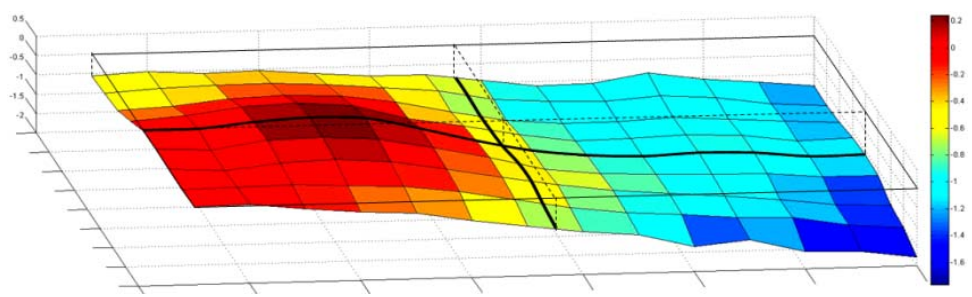

Figure 4. Initial imperfections shape of member B21, web 2

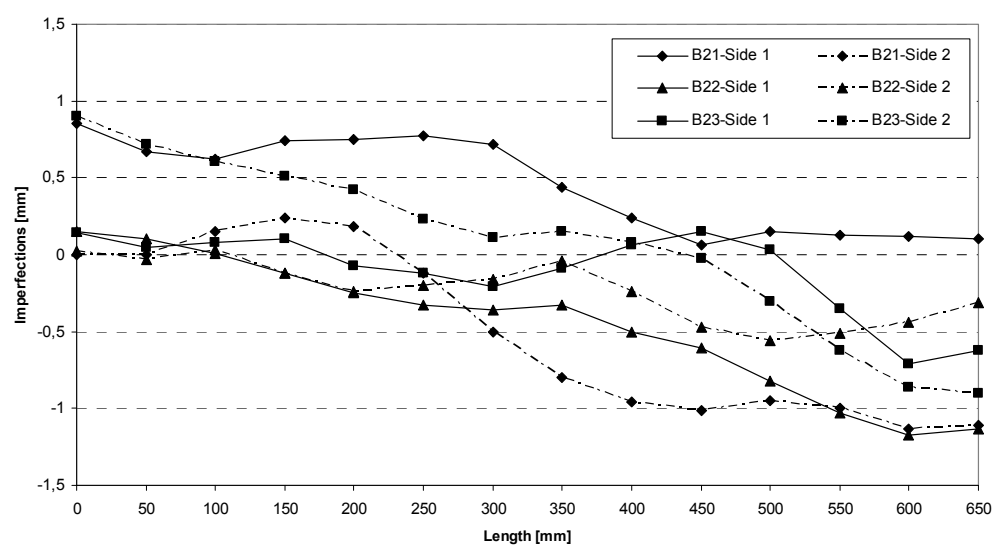

Figure 5. Midline initial imperfections of all webs

The overall analysis of the initial imperfections shape for all tested members indicates that the expected tolerated shape in the relevant standard is theoretical and cannot be achieved in reality. The spatial areas in Figures 3 and 4, also the graphs in Figure 5 clearly show that the initial (production) imperfection is a random variable and must be more precisely reflected in the calculation procedure. For these reasons the detailed theoretical and numerical analysis were necessary to be performed using the software based on the FEM - ANSYS.

\section{Creation of calculation models and the experiment simulation}

The target of the FEM analysis was to obtain more accurate data about the post-critical behaviour of the mentioned members, to determine their limit loads and to compare them with the experimental results. The volume shell finite element SOLSH190, quad and triangular, was used to create the calculation models, geometrical and physical non-linear calculation was applied. The finite element

Al Ali M., Tomko M. Analysis of the Resistance of Thin-Walled Cold-Formed Compressed Steel Members with Closed Cross-sections. Part 2 
SOLSH190 is usually used for the simulation of shell structures with a wide range of thicknesses. This element, with eight connecting nodes has three degrees of freedom at each node, see Figure 6 . The element may be used to solve the geometrical and physical nonlinear problems. This type may be also used for the composite multilayer modelling (up to 250 different material's layers), [5, 6 and 7].

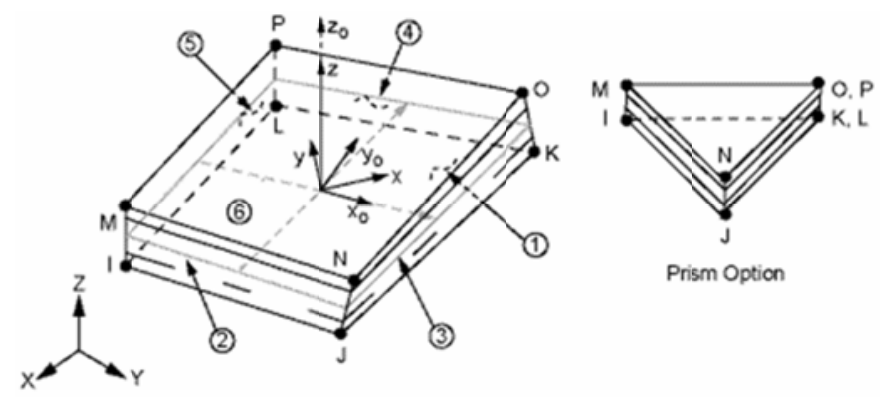

\section{Figure 6. Shell element SOLSH190 and integration points}

Each of the 3D calculation models contains 4182 nodes and 4100 shell elements. Boundary conditions of the modelled, axially compressed members, were defined by two-sided hinged connections. The elastic-plastic material with hardening was considered with the usage of the plastic zone method. This material is characterized by a bilinear approximation of the strain-stress diagram of steel with yield stress fy $=242,33 \mathrm{MPa}$ and hardening modulus Ehard $=2800 \mathrm{MPa}$.

The concept of the generated grid for initial imperfections defining, configuration of a calculation model and the mesh of volume shell finite elements SOLSH190 are presented in Figure 7.

a)

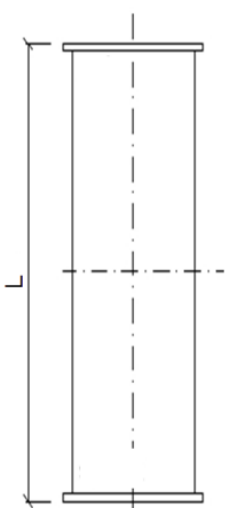

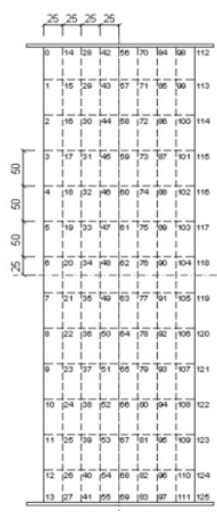

b)

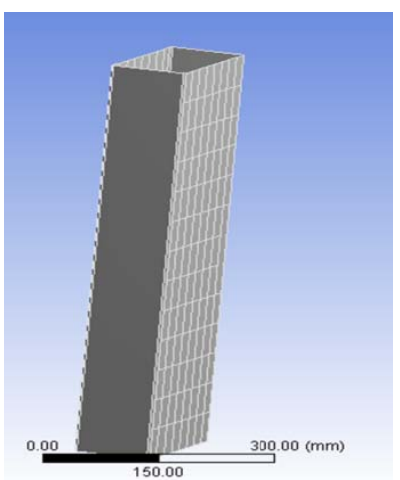

c)

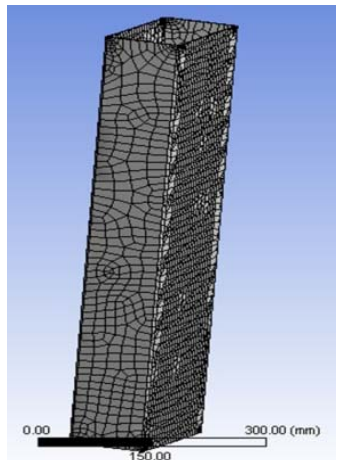

Figure 7. Generated grid (a), configuration of the calculation model (b) and volume shell finite elements mesh (c)

\section{Results and their analysis}

Two types of calculation models were used to verify the initial imperfections:

- Calculation models which consider the initial imperfections of the webs;

- Calculation models which do not consider the initial imperfections of the webs.

The applied load was transformed to the middle-plane of the shell elements with sequential loads increasing up to the initial appearance of the plastic zone (on the internal surface of the web). By a sequence of load increasing, the development of the plastic zone manifested over the external surface of the web. The further overloading effected the broadening of the plastic zones over the web's surface at about $1 / 3$ of the member length. The sequential loading was monitored up to the divergence of the calculation (collapse of the member), [8].

The final web buckling shapes in a topographical form, together with the equivalent elastic strain of modelled member B23 is presented in Figure 8. Figure 9 illustrates the equivalent stress and plastic strain of the mentioned member. 

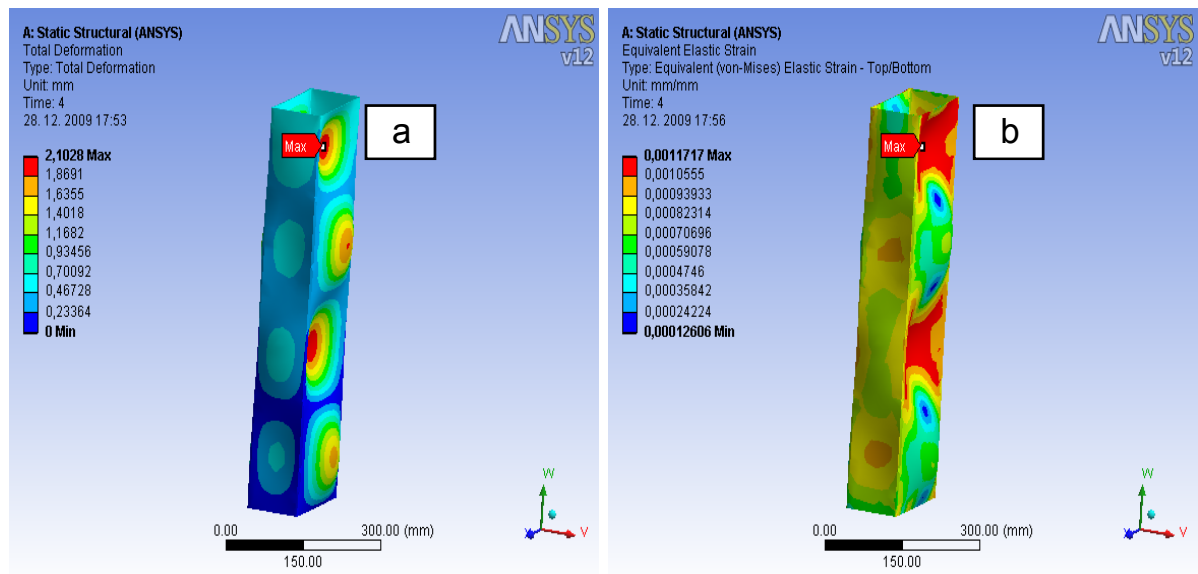

Figure 8. Final deformation (a) and equivalent elastic strain (b), member B23
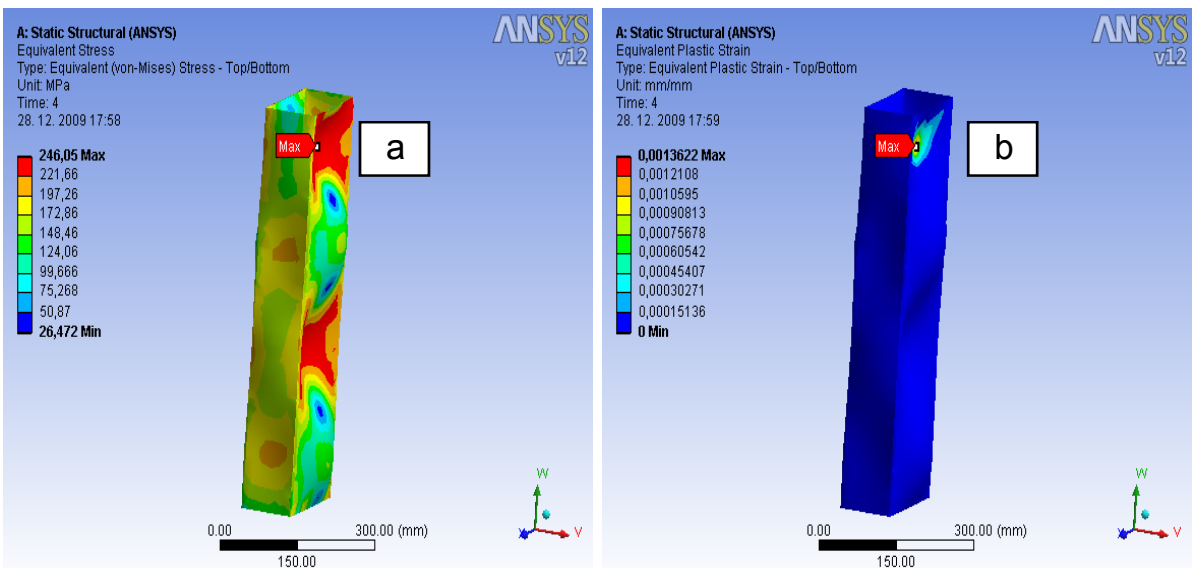

Figure 9. Equivalent stress (a) and equivalent plastic strain (b), member B23

Figure 10 illustrates the individual limit loads, obtained by the calculation according to relevant standards, [9, 10 and 11], by (FEM) numerical simulations and by the experimental investigation of tested members B21, B22 and B23. From Figure 10 it is evident, that the experimental limit loads of individual tested members are smaller than the limit loads obtained by relevant standards.

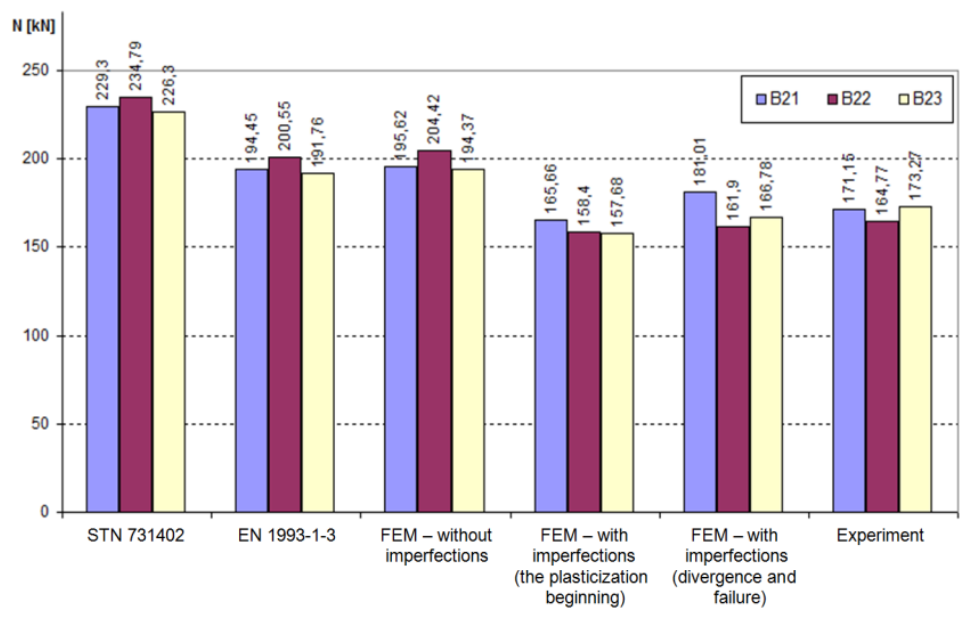

Figure 10. Comparison of individual limit loads of members B21, B22 and B23

Figure 10 also presents the influence of initial imperfections through the process of 3D FEM simulations. The results' correlation between FEM simulation, without considering the initial imperfections, and theoretical calculation according to EN 1993-1-3:2006 means that the Standard neglects the effect of initial imperfections, or does not consider them when they are not of a sinusoidal shape with a size limitation up to $b / 50$.

Al Ali M., Tomko M. Analysis of the Resistance of Thin-Walled Cold-Formed Compressed Steel Members with Closed Cross-sections. Part 2 


\section{Conclusion}

1. Based on the obtained experimental results, data acquired from the calculation models and from the theoretical-numerical analysis, it is evident that the resistances of compressed thin-walled coldformed steel members are significantly influenced by the initial imperfections and/or by the initial buckling shapes of their individual webs.

2. Figure 10 indicates the results' correlation between FEM simulation, without considering the initial imperfections, and theoretical calculation according to EN 1993-1-3:2006. This Figure also indicates the correlation between experimental results and FEM simulation, taking the initial imperfections into consideration. The FEM simulation proves that the calculation procedures in the relevant standards are not sufficient enough to consider the influence that the initial imperfections have on the calculation process.

3. The maximal discrete measured imperfection of all webs was smaller than the maximal tolerated value, provided by the standard EN 1090-2 + A1:2012-03 as b/50. Although this condition has been met, the results revealed a serious effect of the initial imperfections. The expected tolerated buckling shape in this standard is theoretical and cannot be achieved because the initial (production) imperfection is a random variable and must be more precisely reflected in the calculation.

4. The obtained results broadens the knowledge referring to the elastic-plastic resistances of thinwalled cold-formed steel members, as well as the influence of their initial imperfections. The obtained knowledge encourages more consistent and thorough analysis, oriented toward determining real tolerance values and shapes of initial imperfections for these profiles and members.

This paper is prepared within the research project VEGA 1/0582/13 "The elastic-plastic behaviour of compressed thin-walled cold-formed steel elements and stress-strain analysis of welded steel beams", supported by the Scientific Grant Agency of ME SR and SAS.

\section{References}

1. Al Ali M., Tomko M., Demjan I., Badák M. Analysis of the resistance of thin-walled cold-formed compressed steel members with closed cross-sections - Part 1. Magazine of Civil Engineering. 2013. No.5(40). Pp. 38-43.

2. Al Ali M., Tomko M., Badák M. Investigation and analysis of the resistance of compressed cold-formed steel members. The research of the Institute of structural engineering. Košice, Slovakia, 2010, Pp. 13-18

3. Al Ali M., Tomko M., Demjan I. Resistance of Compressed Thin-Walled Cold-Formed Steel Members with Regard to the Influence of Initial Imperfections. Design, Fabrication and Economy of Metal Structures: International Conference Proceedings. Miskolc, Hungary, Springer, 2013. Pp. 113-119.

4. EN 1090-2 + A1:2012: Execution of steel structures and aluminium structures - Part 2: Technical requirements for steel structures, CEN, Brussels 2011 + National Annex A1.

5. Al Ali M., Tomko M., Demjan I., Badák M. Stress-strain analysis of thin-walled compressed steel members with closed cross-sections. SSP Journal of Civil Engineering. 2011. Issue 1. Pp. 85-96.

6. ANSYS Inc. Theory. Release 9.0 [online], Canonsburg: November 2004.1062 p. http://www1.ansys.com/customer/content/documentation/90/ansys/a_thry $90 . p d f$.

7. ANSYS Inc. Release 11.0 Documentation for ANSYS [online], 2011: www.kxcad.net.

8. Al Ali M [et al]. Thin-walled cold-formed compressed steel members and the problem of initial imperfections. Procedia Engineering. 2012. Vol. 40. Pp. 8-13.

9. STN 73 1402:1988. Design of thin-walled profiles in steel structures. UNM, Prague, 1987.

10. EN 1993-1-3:2006. Design of steel structures - Part 3: Supplementary rules for cold-formed members and sheeting. CEN, Brussels, 2006.

11. EN 1993-1-5:2006. Design of steel structures - Part 5: Plated structural elements. CEN, Brussels, 2006.

12. Mamalis A.G., Manolakos D.E., Ioannidis M.B., Kostazos P.K., Dimitriou C. Finite element simulation of the axial collapse of metallic thin-walled tubes with octagonal cross-section. Thin-Walled Structures. 2003. Vol. 41. Issue 10. Pp. 891-900.

Al Ali M., Tomko M. Analysis of the Resistance of Thin-Walled Cold-Formed Compressed Steel Members with Closed Cross-sections. Part 2 
13. Rasmussen J.R. Kim. Bifurcation of locally buckled point symmetric columns. Experimental investigations. Thin-Walled Structures. 2006. Vol. 44. Issue 11. Pp. 1175-1184.

14. Chen Ju, Young Ben: Cold-formed steel lipped channel columns at elevated temperatures. Engineering Structures. 2007. Vol. 29. Issue 7. Pp. 2445-2456.

15. Nuno Silvestre, Young Ben, Camotima Dinar. Non-linear behaviour and load-carrying capacity of CFRPstrengthened lipped channel steel columns. Engineering Structures. 2008. Vol. 30. Issue 10. Pp. 2613-2630.

16. Kwon Young Bong, Kim Bong Sun, Hancock Gregory J. Compression tests of high strength cold-formed steel channels with buckling interaction. Journal of Constructional Steel Research. 2009. Vol. 65. Issue 2. Pp. 278-289.

17. Rogers C.A., Yang D., Hancock G.J. Stability and ductility of thin high strength G550 steel members and connections. Thin-Walled Structures. 2003. Vol. 41. Issues 2-3. Pp. 149-166.

18. DiPaolo B.P., Tom J.G. A study on an axial crush configuration response of thin-wall, steel box components: The quasi-static experiments. International Journal of Solids and Structures. 2006. Vol. 43. Issues 25-26. Pp. 7752-7775.

19. Yuan-Qi Lia, Zu-Yan Shena, Lei Wanga, Yan-Min Wangb, Hong-Wei Xuc. Analysis and design reliability of axially compressed members with high-strength cold-formed thin-walled steel. Thin-Walled Structures. 2007. Vol. 45. Issue 4. Pp. 473-492.

20. Gardner L., Saari N., Wang F.: Comparative experimental study of hot-rolled and cold- formed rectangular hollow sections. Thin-Walled Structures. 2010. Vol. 48. Issue 7. Pp. 495-507.

21. Young Ben, Rasmussen J.R. Kim. Behaviour of cold-formed singly symmetric columns. Thin-Walled Structures. 1999. Vol. 33. Issue 2. Pp. 83-102.

22. Young Ben, Rasmussen J.R. Kim. Inelastic bifurcation of cold-formed singly symmetric columns. ThinWalled Structures. 2000. Vol. 36. Issue 3. Pp. 213-230.

23. Young Ben, Ellobody Ehab: Design of cold-formed steel unequal angle compression members. ThinWalled Structures. 2007. Vol. 45. Issue 3. Pp. 330-338.

24. Zhang Yaochun, Wang Chungang, Zhang Zhuangnan. Tests and finite element analysis of pin-ended channel columns with inclined simple edge stiffeners. Journal of Constructional Steel Research. 2007. Vol. 63. Issue 3. Pp. 383-395.

25. Jurgen Becque, Maura Lecce, Rasmussen J.R. Kim. The direct strength method for stainless steel compression members. Journal of Constructional Steel Research. 2008. Vol. 64. Issue 11. Pp. 12311238.

26. Juhás P. [et al]. The elastic-plastic behaviour and stress-strain analysis of framed and flat structural members made from steel and composite materials. Research report VEGA 1/0673/10. Košice, 20102011.

Mohamad Al Ali, Košice, Slovakia Phone number: +421905359228; e-mail: mohamad.alali@tuke.sk

Michal Tomko, Košice, Slovakia Phone number: +421556024249; e-mail: michal.tomko@tuke.sk

(C) Al Ali M., Tomko M., 2014

Al Ali M., Tomko M. Analysis of the Resistance of Thin-Walled Cold-Formed Compressed Steel Members with Closed Cross-sections. Part 2 